\title{
MODELLING OF CRITICAL VELOCITIES OF THE CARDAN MECHANISM USING TRANSFER MATRIX METHOD
}

\author{
Petr Hrubý1, Tomáš Náhlík²,* \\ ${ }^{1}$ Department of Mechanical Engineering, Institute of Technology and Business, Ceske Budejovice, Czech Republic \\ ${ }^{2}$ Department of Informatics and Natural Sciences, Institute of Technology and Business, Ceske Budejovice, \\ Czech Republic \\ *E-mail of corresponding author: nahlik@mail.vstecb.cz
}

\section{Resume}

The presented paper focuses to rotating components of mechanical constructions. The problem of the spatial combined bending-gyratory vibration and calculation of the Eigen frequencies is studied. The model of Cardan Mechanism is solved by the transfer matrix method. Transfer matrices were derived for shaft, concentrated mass and elastic bearing. The physical and mechanical properties of each part of the mechanism are hidden in these matrices. A procedure for calculating Eigen frequencies was proposed.

\section{Article info}

Received 9 April 2020

Accepted 17 June 2020

Online 10 November 2020

\section{Keywords:}

critical velocities, cardan mechanism, transfer matrix method, eigen frequencies, vibrations, automotive

\section{Introduction}

In mechanical constructions, the most endangered parts are rotating components, e.g. shafts [1]. Reliability of a shaft is endangered in particular in the two limit states. In the vicinity of resonance, there is an enormous increase in the amplitudes of the state variables and reaching of the yield strength of a material. These conditions often occur with the coupling shafts of Cardan mechanisms. The torque is transmitted here over long distances. Shafts are long and slender and are prone to transverse bending. The gearbox shafts are compact and operate at a sufficient distance from the resonant area. In that case, they are threatened by fatigue fractures; they need to be checked for safety to fatigue. A similar situation to gearboxes is with the gear pump shafts.

Mathematical models of the Cardan mechanism lead to solutions from the field of linear algebraic equations. In the case of bending oscillations, the motion equation of the basic element is a partial differential equation of the 4th order for the variables $x$ and $t$ [2]. An analytical solution for simpler cases can be used.

It seems appropriate, for this case, to use the transfer matrix method. This method does not increase the matrix size (matrix $4 \times 4$ for planar oscillation, $8 \times 8$ for spatial oscillation), resulting in the lower hardware requirements. The transfer matrix method uses a combination of analytical and numerical methods. The benefit of this calculation is a possibility to obtain deformations caused by external excitation and dynamic deformation and stress analysis. Using the transfer matrix method is relatively easy to get a solution to the whole system (the whole Cardan mechanism). Another advantage is that it can be combined with the method of the imaginary slice, which analytically solves the differential equations of motion for a smooth shaft (smooth continuum - a constant diameter), the transfer matrices for the shaft, matrices of concentrated mass and the elastic bearing, which are the basic structural elements of a dynamic model of shafts, are derived.

This paper is devoted to studying the problem spatial combined bending-gyratory vibration and calculation of the Eigen frequencies using the transfer matrix method.

\section{Spatial combined bending-gyratory vibration}

The element (see Figure 1) is an one-dimensional continuum with geometrical parameters as inner radius $r_{1}$, outer radius $r_{2}$ and length $l$. The physical parameters are $E$ module of elasticity and density $\rho$. The whole system is rotating with angular velocity $\omega$.

External forces, acting on the element, create a state of the combined bending-gyratory vibration. The continuum element is making general spatial motion which is composed 


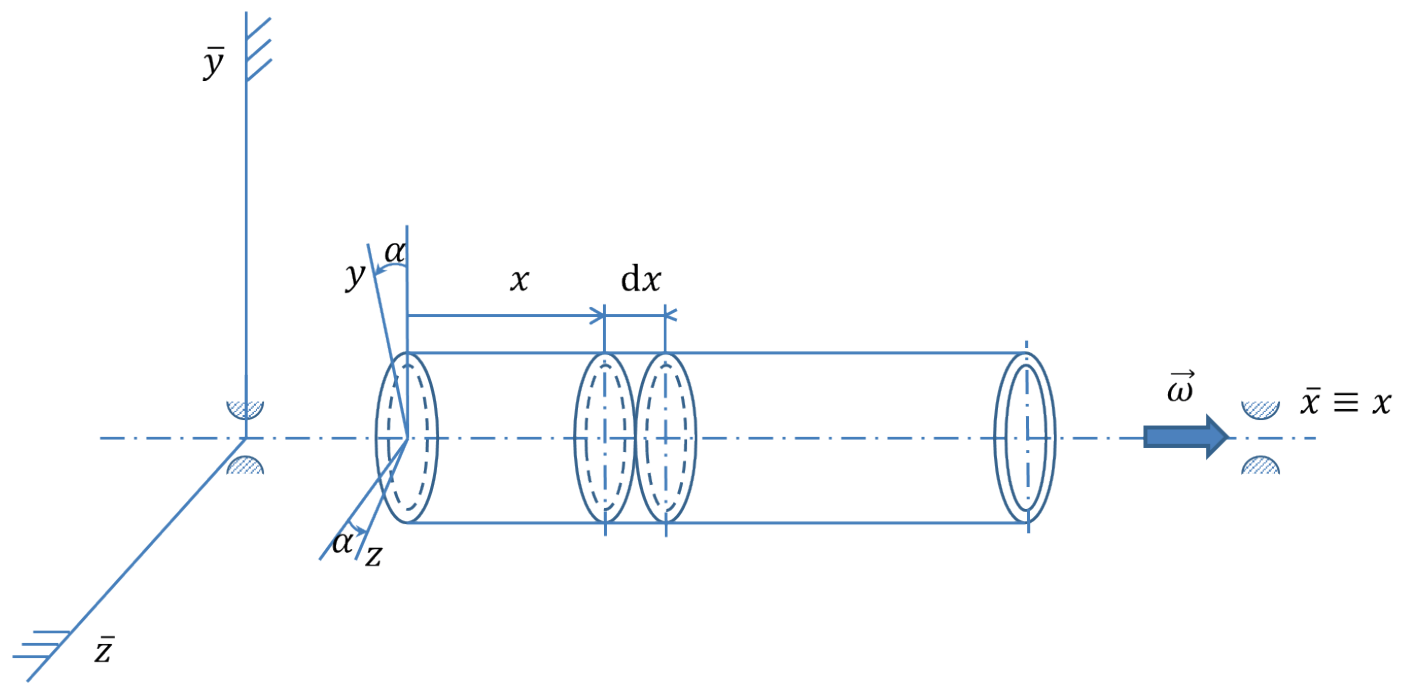

Figure 1 The element of the continuum

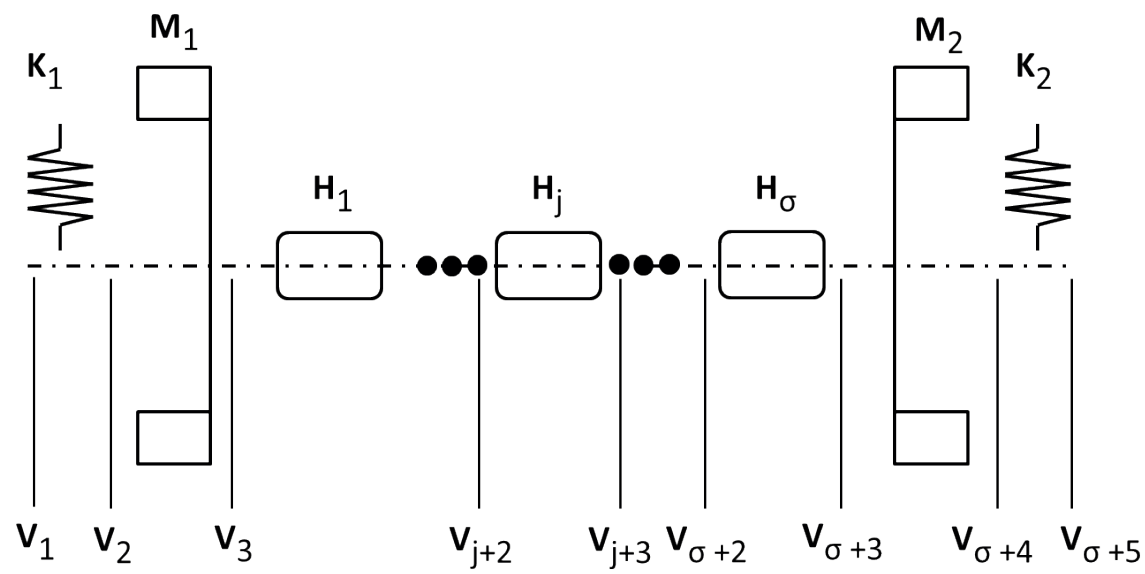

Figure 2 Model of the whole Cardan mechanism

of three simple movements - namely rotation, shift and spherical motion.

The following formula represents the equation of motion in the state of spatial combined bending-gyratory vibrations [2]

$$
\begin{aligned}
& \frac{\partial^{4} v}{\partial x^{4}}-\frac{\rho}{E}\left(\frac{\partial^{4} v}{\partial x^{2} \partial t^{2}}+\omega^{2} \frac{\partial^{2} v}{\partial x^{2}}\right)+ \\
& +\frac{4 \rho}{E\left(r_{2}^{2}+r_{1}^{2}\right)}\left(\frac{\partial^{2} v}{\partial t^{2}}-\omega^{2} v+2 i \omega \frac{\partial v}{\partial t}\right)=0,
\end{aligned}
$$

where

$$
v(x, t)=y(x, t)+i z(x, t) .
$$

For more details see [2].

\section{Derivation of the transfer matrix}

The Transfer Matrix Method (TMM) is a combination of numerical and analytical methods and comes from the exact analytical solution (PDE of $4^{\text {th }}$ order) (see Equation 1).
It is necessary to derive the transfer matrices (matrices are denoted by bold letters, e.g. $\mathbf{H}, \mathbf{M}, \mathbf{K}$ ) for each of the basic structural elements of the Cardan mechanism: shaft $\mathbf{H}$, concentrated mass $\mathbf{M}$ and elastic bearing $\mathbf{K}$ (see Figure 2).

One needs to define the vector of state $\mathbf{V}_{i}$ on the edge cuts of each element based on amplitudes of state variables.

Vector of state (see Equation (2)):

$\mathbf{V}(x, t)=\mathbf{V}(x) e^{i \bar{\omega} t}, \mathbf{V}(x)=[\mathbf{Y}(x) \mid \mathbf{Z}(x)]$,

$\mathbf{V}(x)=\left[\begin{array}{c}y(x) \\ y^{\prime}(x) \\ -M_{z}(x) \\ -Q_{y}(x)\end{array}\right], \mathbf{Z}(x)=\left[\begin{array}{c}z(x) \\ z^{\prime}(x) \\ -M_{y}(x) \\ -Q_{z}(x)\end{array}\right]$,

where $y(x)$ is the amplitude of deflection, $y^{\prime}(x)$ is the slope of deflection, $M_{z}(x)$ is the amplitude of the bending moment and $Q_{y}(x)$ is the moving force.

Relationship between neighbouring state vectors is $\mathbf{V}_{i+1}=\mathbf{H}_{j} \mathbf{V}_{i}$, where $j=1, \ldots, \sigma, i, i=j+2, \mathbf{V}_{2}=\mathbf{K}_{1} \mathbf{V}_{1}$, $\mathbf{V}_{3}=\mathbf{M}_{1} \mathbf{V}_{2} \ldots, \mathbf{V}_{\sigma+5}=\mathbf{P} \cdot \mathbf{V}_{1}$.

The method uses knowledge of boundary conditions of the state vectors of the joint shaft. The frequency 
equation can then be determined from the coupling relations between the edge state vectors. The first and the last state vectors of the dynamic model are $\mathbf{V}_{1}$, resp. $\mathbf{V}_{\sigma+5}$, $\mathbf{V}_{1}\left[v_{1}(0), v_{1}^{\prime}(0), 0,0\right]^{\mathrm{T}}, \mathbf{V}_{\sigma+5}=\left[0,0, v_{0}\left(l_{0}\right), v_{0}^{\prime}\left(l_{0}\right)\right]$.

States vectors $\mathbf{V}_{1}$ and $\mathbf{V}_{\sigma+5}$ are joint

$\mathbf{V}_{\sigma+5}=\mathbf{P} \cdot \mathbf{V}_{1}$

The Transfer Matrix $\mathbf{P}$ is:

$\mathbf{P}=\mathbf{K}_{2} \cdot \mathbf{M}_{2} \cdot \mathbf{H}_{\sigma} \ldots \mathbf{H}_{j} \ldots \mathbf{H}_{1} \cdot \mathbf{M}_{1} \cdot \mathbf{K}_{1}$.

$\mathbf{P}=\left[\begin{array}{cc}\mathbf{P}_{y} & 0 \\ 0 & \mathbf{P}_{z}\end{array}\right], \mathbf{P}_{y}=\mathbf{P}_{z}=\left[p_{i j}\right]_{1}^{4}$

All the matrices in Equation (5) are of the $8 \times 8$ type. Equation (5) describes a system of eight equations of eight unknowns. The matrix $\mathbf{P}$ is blocked diagonal, so this system can be divided into two systems of 4 equations by 4 unknowns. Each system describes the movement of individual axes.

After entering the edge vectors, the transfer matrix and matrix multiplication are
$\mathbf{A}_{y} \cdot \mathbf{B}_{y}=\mathbf{D}_{y}, \mathbf{A}_{z} \cdot \mathbf{B}_{z}=\mathbf{D}_{z}$

\section{Solution to the problem}

The following matrices, concerning Equations (5) to (7), are obtained.

$$
\begin{aligned}
& \mathbf{A}_{y}=\mathbf{A}_{z}\left[\begin{array}{lllc}
p_{11} & p_{12} & -1 & 0 \\
p_{21} & p_{22} & 0 & -1 \\
p_{31} & p_{32} & 0 & 0 \\
p_{41} & p_{42} & 0 & 0
\end{array}\right] . \\
& \mathbf{B}_{y}=\left[\begin{array}{l}
y_{1}(0) \\
y_{1}^{\prime}(0) \\
y_{0}\left(l_{0}\right) \\
y_{0}^{\prime}\left(l_{0}\right)
\end{array}\right], \mathbf{B}_{z}=\left[\begin{array}{l}
z_{1}(0) \\
z_{1}^{\prime}(0) \\
z_{0}\left(l_{0}\right) \\
z_{0}^{\prime}\left(l_{0}\right)
\end{array}\right] . \\
& \mathbf{D}_{y}=M_{1 z} \cdot\left[\begin{array}{c}
p_{13} \\
p_{23} \\
p_{34}-M_{2 z} / M_{1 z} \\
p_{43} \\
p_{13} \\
p_{23} \\
\mathbf{D}_{z}=M_{2 y} / M_{1 y} \\
p_{43}
\end{array}\right],
\end{aligned}
$$

The solution of the left edge of the joint shaft is:

$$
y_{1}(0)=\frac{p_{42}\left(p_{33} M_{1 z}-M_{2 z}\right)-p_{32} p_{43} M_{1 z}}{p_{31} p_{42}-p_{32} p_{41}} .
$$

$y_{1}^{\prime}(0)=\frac{p_{31} p_{43} M_{1 z}-p_{41}\left(p_{33} M_{1 z}-M_{2 z}\right)}{p_{31} p_{42}-p_{32} p_{41}}$.

$z_{1}(0)=\frac{p_{42}\left(p_{33} M_{1 y}-M_{2 y}\right)-p_{32} p_{43} M_{1 y}}{p_{31} p_{42}-p_{32} p_{41}}$.

$z_{1}^{\prime}(0)=\frac{p_{31} p_{43} M_{1 y}-p_{41}\left(p_{33} M_{1 y}-M_{2 y}\right)}{p_{31} p_{42}-p_{32} p_{41}}$.

\section{The transfer matrix for a shaft}

The transfer matrices for shafts parts have the following form

$$
\begin{aligned}
& \mathbf{H}(x)=\left[\begin{array}{cc}
\mathbf{H}_{y}(x) & 0 \\
0 & \mathbf{H}_{z}(x)
\end{array}\right], \mathbf{H}_{y}=\mathbf{H}_{z}= \\
& =\left[\mathbf{H}_{11}\left|\mathbf{H}_{12}\right| \mathbf{H}_{13} \mid \mathbf{H}_{14}\right]
\end{aligned}
$$

$$
\mathbf{H}_{11}=\frac{1}{\beta_{1}^{2}+\beta_{2}^{2}}\left[\begin{array}{c}
\beta_{2}^{2} \cosh \beta_{1} l+\beta_{1}^{2} \cos \beta_{2} l \\
\beta_{1} \beta_{2}\left(\beta_{2} \sinh \beta_{1} l-\beta_{1} \sin \beta_{2} l\right) \\
E J \beta_{1}^{2} \beta_{2}^{2}\left(\cosh \beta_{1} l-\cos \beta_{2} l\right) \\
E J \beta_{1}^{2} \beta_{2}^{2}\left(\beta_{1} \sinh \beta_{1} l+\beta_{2} \sin \beta_{2} l\right)
\end{array}\right],
$$

$$
\mathbf{H}_{12}=\frac{1}{\beta_{1}^{2}+\beta_{2}^{2}}\left[\begin{array}{c}
\beta_{2}^{2} / \beta_{1} \sinh \beta_{1} l+\beta_{1}^{2} / \beta_{2} \sin \beta_{2} l \\
\beta_{2}^{2} \cosh \beta_{1} l+\beta_{1}^{2} \cos \beta_{2} l \\
E J \beta_{1} \beta_{2}\left(\beta_{2} \sinh \beta_{1} l-\beta_{1} \sin \beta_{2} l\right) \\
E J \beta_{1}^{2} \beta_{2}^{2}\left(\cosh \beta_{1} l+\cos \beta_{2} l\right)
\end{array}\right],
$$

$\mathbf{H}_{13}=\frac{1}{\beta_{1}^{2}+\beta_{2}^{2}}\left[\begin{array}{c}1 / E J\left(\cosh \beta_{1} l-\cos \beta_{2} l\right) \\ 1 / E J\left(\beta_{1} \sinh \beta_{1} l+\beta_{2} \sin \beta_{2} l\right) \\ \beta_{1}^{2} \cosh \beta_{1} l+\beta_{2}^{2} \cos \beta_{2} l \\ \beta_{1}^{3} \sinh \beta_{1} l+\beta_{2}^{3} \sin \beta_{2} l\end{array}\right]$,

$$
\mathbf{H}_{14}=\frac{1}{\beta_{1}^{2}+\beta_{2}^{2}}\left[\begin{array}{c}
1 / E J\left(1 / \beta_{1} \sinh \beta_{1} l-1 / \beta_{2} \sin \beta_{2} l\right) \\
1 / E J\left(\cosh \beta_{1} l+\cos \beta_{2} l\right) \\
\beta_{1} \sinh \beta_{1} l+\beta_{2} l \\
\beta_{1}^{2} \cosh \beta_{1} l+\beta_{2}^{2} \cos \beta_{2} l
\end{array}\right] \text {, }
$$

where:

$$
J=\frac{\pi}{4}\left(r_{2}^{4}-r_{1}^{4}\right)
$$

$\beta_{1}=\left\{-\frac{\rho}{2 E}\left(\overline{\omega^{2}}-\omega^{2}\right)+\right.$

$\left.+\left[\frac{\rho^{2}}{4 E^{2}}\left(\overline{\omega^{2}}-\omega^{2}\right)^{2}+\frac{4 \rho(\bar{\omega}-\omega)^{2}}{E\left(r_{2}^{2}+r_{1}^{2}\right)}\right]^{\frac{1}{2}}\right\}^{\frac{1}{2}}$.

$\beta_{2}=\left\{\frac{\rho}{2 E}\left(\overline{\omega^{2}}-\omega^{2}\right)+\right.$

$\left.+\left[\frac{\rho^{2}}{4 E^{2}}\left(\overline{\omega^{2}}-\omega^{2}\right)^{2}+\frac{4 \rho(\bar{\omega}-\omega)^{2}}{E\left(r_{2}^{2}+r_{1}^{2}\right)}\right]^{\frac{1}{2}}\right\}^{\frac{1}{2}}$. 


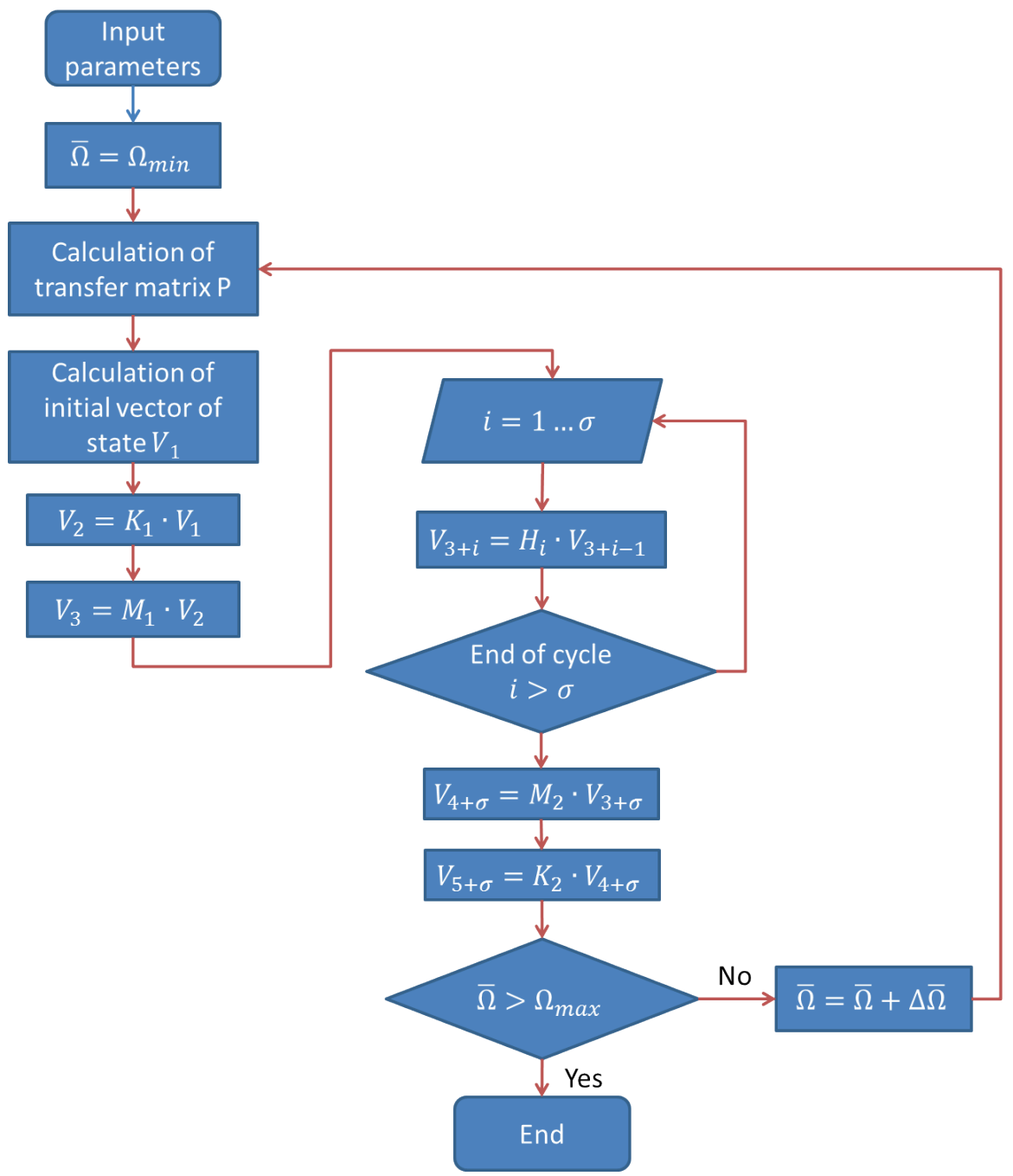

Figure 3 Process of the Eigen frequencies calculations

6 The transfer matrix for the concentrated mass

The matrices for concentrated masses are:

$$
\mathbf{M}=\left[\begin{array}{cc}
\mathbf{M}_{y} & 0 \\
0 & \mathbf{M}_{z}
\end{array}\right] \text {. }
$$

$$
\begin{aligned}
& \mathbf{M}_{y}=\mathbf{M}_{z}=\left[\begin{array}{cc}
1 & 0 \\
0 & 1 \\
0 & -J_{1} \omega^{2}+\left(J_{0}-J_{1}\right) \omega^{2} \\
m\left(\bar{\omega}+\omega^{2}\right) & 0
\end{array}\right. \\
& \begin{array}{ll}
0 & 0
\end{array} \\
& \begin{array}{ll}
0 & 0
\end{array} \\
& 10 \\
& \begin{array}{ll}
0 & 1
\end{array}
\end{aligned}
$$

\section{$7 \quad$ Transfer matrix for elastic bearing}

Matrices for the elastic bearing can be expressed as:

$$
\mathbf{K}(x)=\left[\begin{array}{cc}
\mathbf{K}_{y} & 0 \\
0 & \mathbf{K}_{z}
\end{array}\right] .
$$

$$
\mathbf{K}_{y}=\mathbf{K}_{z}=\left[\begin{array}{cccc}
1 & 0 & 0 & 0 \\
0 & 1 & 0 & 0 \\
0 & 0 & 1 & 0 \\
-k & 0 & 0 & 1
\end{array}\right] .
$$

\section{Eigen frequencies}

Rewriting of Equation (8) leads to the following equation

$\mathbf{F} \cdot \mathbf{V}=0$

and

$\mathbf{V}=\left[v(0), v^{\prime}(0), v_{0}\left(l_{0}\right), v_{0}^{\prime}\left(l_{0}\right)\right]^{T}$

One obtains set of equations ( 4 homogeneous equations of 4 unknowns) with matrix

$\mathbf{F}=\left[\begin{array}{cccc}p_{11} & p_{12} & -1 & 0 \\ p_{21} & p_{22} & 0 & -1 \\ p_{31} & p_{32} & 0 & 0 \\ p_{41} & p_{42} & 0 & 0\end{array}\right]$ 
Eigen frequencies are the non-trivial solutions of the above sets of equations with matrix Equation (31). Calculation of these solutions goes in a standard way

$$
\operatorname{Det} \mathbf{F}=0
$$

Frequency determinant $\operatorname{det} \mathbf{F}=f(\Omega)$ is a function of $\Omega$. Eigen frequencies of system are solutions of nonlinear algebraic equation $f(\Omega)=0$ (i.e., intersections with axis). The number of solutions is indefinite. Appropriate solutions are found only in the interval $\left(\Omega_{\min }, \Omega_{\max }\right)$.

Process of calculation of $\Omega$ is done in several steps (see Figure 3).

It is sufficient to take $\Delta \Omega$ of the order of one hundredth to a thousandth of the length $\left(\Omega_{\max }-\Omega_{\min }\right)$ of the frequency interval.

If the signum of the function $f(\Omega)$ changes between $\Omega_{\min }+j \cdot \Delta \Omega$ and $\Omega_{\min }+(j+1) \cdot \Delta \Omega(j=0,1,2 \ldots)$, $\Delta \Omega$ must be reduced to $\frac{1}{10}$ and the process is repeated with the value $\frac{\Delta \Omega}{10}$. The calculation is finished when $\left|\frac{f}{f_{\text {min }}}\right|<\varepsilon<1$.

\section{Conclusions}

Modelling of the rotating shaft is influenced by many factors, such as workspace of universal joints [3], vibration noise [4], flexibility of a shaft [5], increasing rotation velocity [6].
More frequently separated movements of the shaft are studied (see [1, 7-9]). Sinitsin and Shestakov [10] present a comprehensive analysis of the angular and linear accelerations of moving elements (shafts, gears) by wireless acceleration sensor of moving elements. The combined motions are presented in paper [2].

A procedure for vibration analysis of the device, based on measured data in simulated operating modes in mechanisms, is studied in [11]. In [12], these new trends in torsional vibration calculation for various vehicles are briefly described, with attention paid not only to practical use but above all to how and to what extent these themes should be presented to students.

In the paper, the following problems are presented:

- Calculation the vector of state in every part of the shaft based on known physical characteristics;

- Calculation of transfer matrix $\mathbf{P}$ and all the other amplitude-frequency characteristics of the state quantity are done in Octave 4.2.0;

- Assessing the resistance of the shaft to transverse oscillation during the design by application of the transfer matrix method.

\section{Acknowledgement}

The work presented in this paper was supported by project IGS-8210-006/2020 of the Institute of Technology and Business in Ceske Budejovice.

\section{References}

[1] ARAB, S. B., RODRIGUES, J. D., BOUAZIZ, S., HADDAR, M. A finite element based on Equivalent Single Layer Theory for rotating composite shafts dynamic analysis. Composite Structures [online]. 2017, 178, p. 135-144. ISSN 0263-8223. Available from: https://doi.org/10.1016/j.compstruct.2017.06.052

[2] HRUBY, P., SMETANOVA, D., NAHLIK, T. Spatial combined bending-gyratory vibration - equations of motion. In Mathematics, Information Technologies and Applied Sciences 2018: post-conference proceedings of extended versions of selected papers. 2018. p. 64 - 69.

[3] ZHANG, G., DU, J., TO, S. Study of the workspace of a class of universal joints. Mechanism and Machine Theory [online]. 2014, 73, p. 244-258. ISSN 0094-114X. Available from: https://doi.org/10.1016/j.mechmachtheory.2013.11.004

[4] ERTURK, A. T., KARABAY, S., BAYNAL, K., KORKUT, T. Vibration noise harshness of a light truck driveshaft, analysis and improvement with six sigma approach. Acta Physica Polonica A [online]. 2017, 131(3), p. 477-480. ISSN 0587-4246. Available from: https://doi.org/10.12693/APhysPolA.131.477

[5] RODRIGUEZ-CIANCA, D., RODRIGUEZ-GUERRERO, C., VERSTRATEN, T., JIMENEZ-FABIAN, R., VANDERBORGHT, B., LEFEBER, D. A Flexible shaft-driven Remote and Torsionally Compliant Actuator (RTCA) for wearable robots. Mechatronics [online]. 2019, 59, p. 178-188. ISSN 0957-4158. Available from: https://doi.org/10.1016/j. mechatronics.2019.04.004

[6] XU, H.-B., TANG, S., XI, H. F., GAO, P.-Y., LI, M.-Y. Joint interface during arc milling brazing of aluminium alloy to low carbon steel with cutter milling at various rotation speeds. Rare Metals [online]. 2017, 36(11), p. 872-877. ISSN 1001-0521, eISSN 1867-7185. Available from: https://doi.org/10.1007/s12598-017-0957-y

[7] GUO, Y., LI, W., YU, S., HAN, X., YUAN, Y., WANG, Z., MA, X. Diesel engine torsional vibration control coupling with speed control system. Mechanical Systems and Signal Processing [online], 2017, 94, p. 1-13. ISSN 0888-3270. Available from: https://doi.org/10.1016/j.ymssp.2017.01.017

[8] HRUBY, P.; NAHLIK, T.; SMETANOVA, D. Mathematical modelling of shafts in drives. Communications-Scientific letters of the University of Zilina [online]. 2018, 20(4), p. 36-40. ISSN 1335-4205, eISSN 2585-7878. Available from: http://komunikacie.uniza.sk/index.php/communications/article/view/637 
[9] HRUBY, P.; NAHLIK, T. Application of the transfer matrix method for modelling Cardan mechanism of a real vehicle. Extended abstract [online] [accessed 2020-04-01]. Available from: https://www.imm.upv.es/wp-content/ uploads/2019/03/Modelling2018.pdf

[10] SINITSIN, V. V.; SHESTAKOV, A. L. Wireless acceleration sensor of moving elements for condition monitoring of mechanisms. Measurement Science and Technology [online]. 2017, 28(9), 094002. ISSN 0957-0233, eISSN $1361-6501$. Available from: https://doi.org/10.1088/1361-6501/aa7ab6

[11] DEKYS, V., KRISKA, P., LIETAVA, L. KOPAS, P. STALMACH, O. Simplified estimate of fatigue damage based on dynamic analysis. Scientific Journal of Silesian University of Technology. Series Transport [online]. 2018, 99, p. 15-23. ISSN 0209-3324, eISSN 2450-1549. Available from: https://doi.org/10.20858/sjsutst.2018.99.2

[12] ZOUL, V., KOVAC, P. A brief overview about the development of torsional vibration calculation and education of methods for their calculation. Scientific Journal of Silesian University of Technology. Series Transport [online]. 2018, 99, p. 205-211. ISSN 0209-3324, eISSN 2450-1549. Available from: https://doi.org/10.20858/sjsutst.2018.99.19 